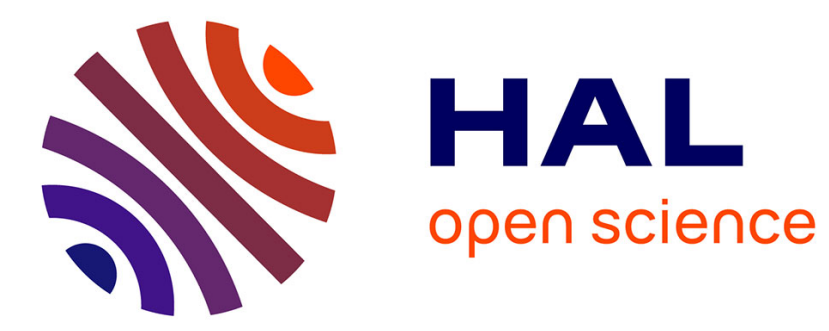

\title{
Multi-scale and multi-technical analysis of the thermal degradation of poly(ether imide)
}

\author{
Emilie Courvoisier, Yoann Bicaba, Xavier Colin
}

\section{To cite this version:}

Emilie Courvoisier, Yoann Bicaba, Xavier Colin. Multi-scale and multi-technical analysis of the thermal degradation of poly(ether imide). Polymer Degradation and Stability, 2018, 147, pp.177-186. 10.1016/j.polymdegradstab.2017.12.002 . hal-01826383

\section{HAL Id: hal-01826383 \\ https://hal.science/hal-01826383}

Submitted on 29 Jun 2018

HAL is a multi-disciplinary open access archive for the deposit and dissemination of scientific research documents, whether they are published or not. The documents may come from teaching and research institutions in France or abroad, or from public or private research centers.
L'archive ouverte pluridisciplinaire HAL, est destinée au dépôt et à la diffusion de documents scientifiques de niveau recherche, publiés ou non, émanant des établissements d'enseignement et de recherche français ou étrangers, des laboratoires publics ou privés. 


\title{
Multi-scale and multi-technical analysis of the thermal degradation of poly (ether imide)
}

\author{
Emilie Courvoisier ${ }^{\mathrm{a}, \mathrm{b}}$, Yoann Bicaba ${ }^{\mathrm{a}}$, Xavier Colin ${ }^{\mathrm{b}, *}$ \\ ${ }^{\text {a }}$ SAFRAN Composites, 33 avenue de la gare, 97601 Itteville, France \\ b Laboratoire PIMM, Arts et Metiers ParisTech, 151 boulevard de l'Hôpital, 75013 Paris, France
}

A R T I C L E I N F O

\section{Keywords:}

PEI

Thermal oxidation

Chain scissions

Crosslinking

Young's modulus

\begin{abstract}
A B S T R A C T
The thermal degradation of PEI has been studied in wide ranges of temperature (between 180 and $250{ }^{\circ} \mathrm{C}$ ) and oxygen partial pressure (between 0.21 and 50 bars). On one hand, the chemical ageing mechanisms have been analysed and elucidated by FTIR spectrophotometry and by differential calorimetry (DSC) on sufficiently thin PEI films (between 10 and $60 \mu \mathrm{m}$ thickness) to be totally free of the effects of oxygen diffusion. As expected, and by analogy with other aromatic polymers of similar chemical structure, oxidation occurs preferentially on the methyl groups of the isopropylidene unit of the bisphenol A part, thus causing the disappearance of their characteristic IR absorption band at $2970 \mathrm{~cm}^{-1}$ and the growth of a new IR absorption band at $3350 \mathrm{~cm}^{-1}$, attributed to alcohols. In addition, oxidation leads successively to a relative predominance of chain scissions and crosslinking, resulting in a non-monotonic change of $\mathrm{T}_{\mathrm{g}}$. On the other hand, the consequences of oxidation on the elastic properties have been analysed and elucidated by micro-indentation on polished cross-sections of PEI plates of $3 \mathrm{~mm}$ thickness. The diffusion control of oxidation leads to the development of profiles of Young's modulus within the sample thickness, which correlate perfectly with the changes in chemical structure determined by FTIR spectrophotometry. However, the increase in Young's modulus in the superficial oxidized layer is not the direct consequence of oxidation but of a physical ageing.
\end{abstract}

\section{Introduction}

The competition in the aeronautical market depends both on economic and ecological issues such as the reduction of costs, on-board weight and fuel consumption. That is the reason why since its origin, the aerospace industry has been looking for new lighter materials with high thermomechanical properties. In this context, the use of composite materials made of organic matrix reinforced with glass or carbon fibers (OMC) has been amplified with the aim of progressively replacing the metallic materials. Initially designed for the fabrication of structural parts (wing, tail, fuselage, etc.), OMCs are now being considered for applications in increasingly harsh thermo-chemical environments, such as areas near heat sources (typically in environments of aircraft engine). However, they will be used only if their long-term durability is clearly demonstrated.

The use of thermoplastic matrices has several advantages, such as the integration of specific functions, but also the assembly of parts of the same or different nature. Among the thermoplastic matrices that can meet the aeronautical specifications, poly(ether imide) (PEI) appears as a serious candidate. Indeed, it is an amorphous polymer with a highly aromatic structure giving it not only high thermomechanical performances $\left(\mathrm{T}_{\mathrm{g}} \approx 217{ }^{\circ} \mathrm{C}\right.$ ), but also a high chemical resistance to the most usual solvents (acetone, toluene, ethyl acetate, etc.) and aeronautical fluids (in particular, Skydrol). The thermal degradation of PEI has been little studied in the literature, almost exclusively in the rubbery state above $300{ }^{\circ} \mathrm{C}$ in inert or in slightly oxygenated atmosphere (typically in air).

The oxidation of PEI, but also of aromatic polymers with a similar chemical structure, occurs mainly at the methyl groups of the isopropylidene unit of the bisphenol A part, which contains the most labile $\mathrm{H}$ atoms $[1,2]$. Oxidation leads to the formation of a wide variety of degradation products detected by FTIR spectrophotometry. These products include carbonyls, especially aromatic (at $1690 \mathrm{~cm}^{-1}$ ) and aliphatic ketones $\left(1724 \mathrm{~cm}^{-1}\right)$ and anhydrides $\left(1840\right.$ and $\left.1860 \mathrm{~cm}^{-1}\right)$, as well as hydroxyls (3553 and $3514 \mathrm{~cm}^{-1}$ ) [2-6]. The disappearance of the IR absorption bands which are characteristic to the isopropylidene unit $\left(\mathrm{C}-\mathrm{CH}_{3}\right.$ bond at $1186 \mathrm{~cm}^{-1}$ ) and methyl groups (C-H bond at 2870 , 2933 and $2970 \mathrm{~cm}^{-1}$ ) has been also observed [3,5].

Mechanisms of chain scission were also proposed to explain the formation of the wide variety of volatile products. Chain scissions occur at the $\mathrm{C}$-C bonds of the isopropylidene unit, but also at the ether bonds

\footnotetext{
* Corresponding author.

E-mail address: xavier.colin@ensam.eu (X. Colin).
} 

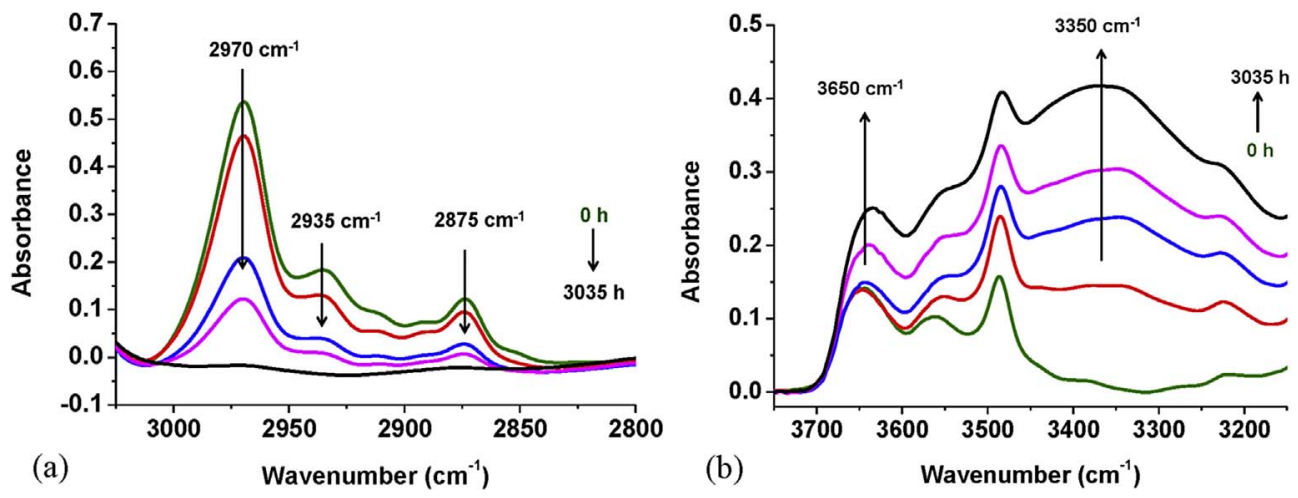

Fig. 1. Changes in the regions of $\mathrm{C}-\mathrm{H}$ (a) and $\mathrm{O}-\mathrm{H}$ bonds (b) in the FTIR spectrum of PEI during its thermal ageing in air at $250{ }^{\circ} \mathrm{C}$.
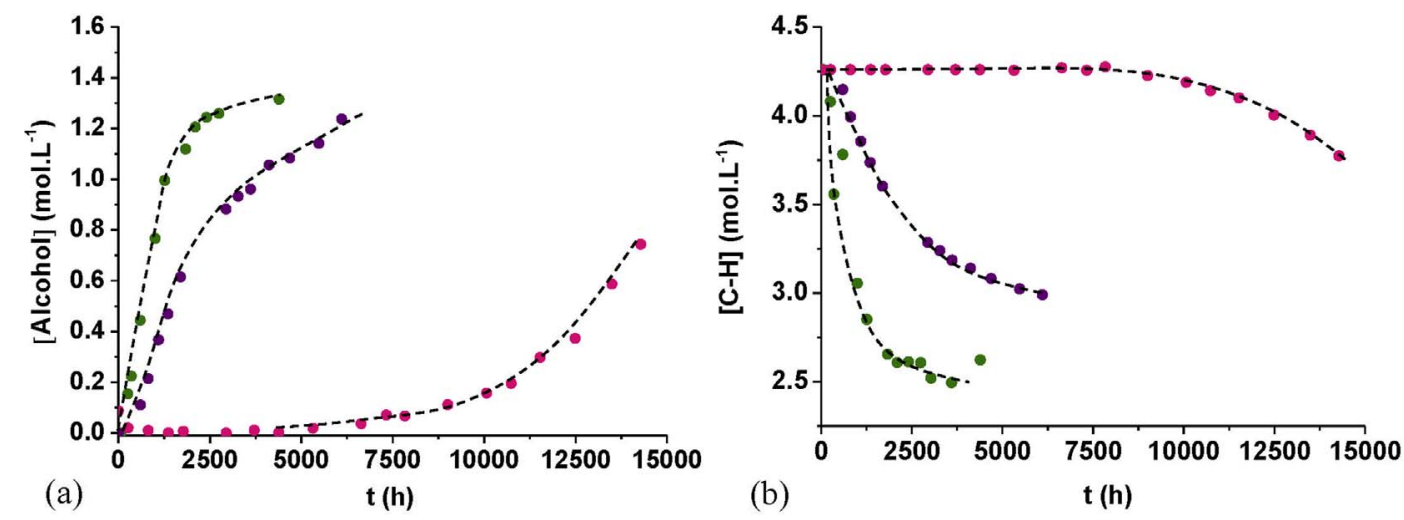

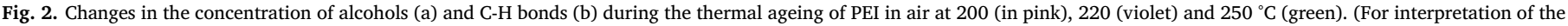
references to colour in this figure legend, the reader is referred to the Web version of this article.)

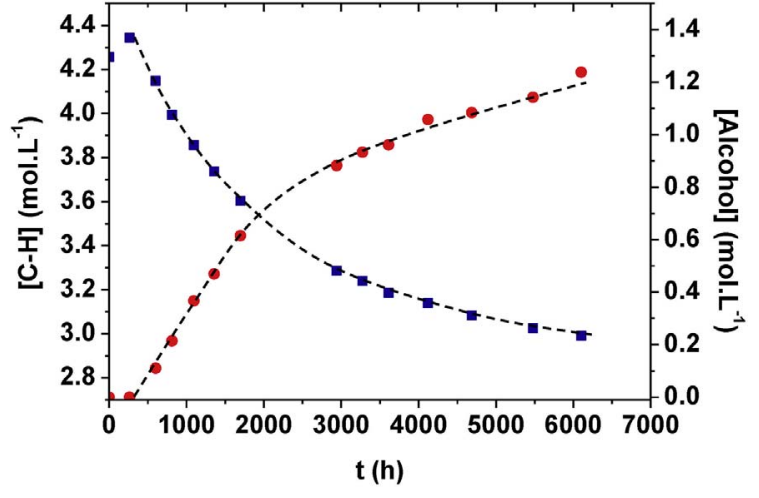

Fig. 3. Comparison between the changes in the concentration of $\mathrm{C}-\mathrm{H}$ bonds $(\square)$ and alcohols (⿶) during the thermal ageing of PEI in air at $220{ }^{\circ} \mathrm{C}$.

between the phenyl and phthalimide rings [1,6-9]. They predominate largely over crosslinking at the beginning of exposure, but they become finally negligible in comparison to crosslinking at longer term $[1,5,7,10,11]$. The bimolecular recombination of methylene radicals would be the main source of crosslinking.

The present article provides a detailed multi-scale and multi-technical analysis of the thermal degradation of PEI at lower temperatures and higher partial oxygen pressures than those studied until now in the literature. A peculiar attention is paid to the consequences of degradation on two key thermomechanical properties in the aeronautical field: the changes in the glass transition temperature and Young's modulus.

\section{Experimental}

The material under study is the PEI ULTEM ${ }^{\circledR} 1010$ supplied by SABIC company in the form of pellets. Plates of $3 \mathrm{~mm}$ thickness were molded by an injection machine from these pellets by the Pôle Européen de Plasturgie (PEP) located in Oyonnax (France). The plates were then cut with a LEICA RM2255 microtome in order to obtain sufficiently thin films (typically between 10 and $60 \mu \mathrm{m}$ thickness) for ensuring a homogeneous oxidation throughout their thickness. The oxidation kinetics of PEI was studied in the rubber state at 220 and $250{ }^{\circ} \mathrm{C}$, but also in the glassy state at 180 and $200{ }^{\circ} \mathrm{C}$, under oxygen partial pressures ranged between 0.21 bar (in air-ventilated ovens regulated at $\pm 1{ }^{\circ} \mathrm{C}$ ) and 50 bars (in autoclaves). All the films were periodically removed from the ageing chambers and cooled to room temperature in a desiccator containing silica gel for preventing any moisture recovery prior to being characterized. It is noteworthy that much thicker samples (plates of $3 \mathrm{~mm}$ thickness) were also exposed in air-ventilated ovens at 220 and $250{ }^{\circ} \mathrm{C}$ in order to put in evidence the development of oxidation profiles. In all cases, the consequences of oxidation were analysed by several complementary laboratory techniques from the molecular to the macroscopic scales, via the macromolecular and microscopic scales.

The changes in molecular structure were followed by FTIR spectrophotometry in a transmission mode. The FTIR spectra of the PEI films were measured before and after ageing for detecting and quantifying the disappearance of chemical groups initially present in the PEI matrix and the formation of the main oxidation products. The analyzes were carried out with a Perkin Elmer Frontier apparatus between 400 and $4000 \mathrm{~cm}^{-1}$, after having averaged the 16 recordings obtained with a minimum resolution of $4 \mathrm{~cm}^{-1}$. The thermal ageing of PEI leads to two major changes in the FTIR spectrum (Fig. 1). On the one hand, it can be seen the decrease in intensity of the IR absorption bands at 2970, 2935 and $2875 \mathrm{~cm}^{-1}$, which are mainly characteristic of the C-H bonds of the $-\mathrm{CH}_{3}$ groups of the isopropylidene unit in the early periods of exposure, but also of the $\mathrm{C}-\mathrm{H}$ bonds of the $-\mathrm{CH}_{2^{-}}$groups formed during thermal ageing at longer term (see Fig. 4). On the other hand, it is observed the appearance and growth of a wide IR absorption band 


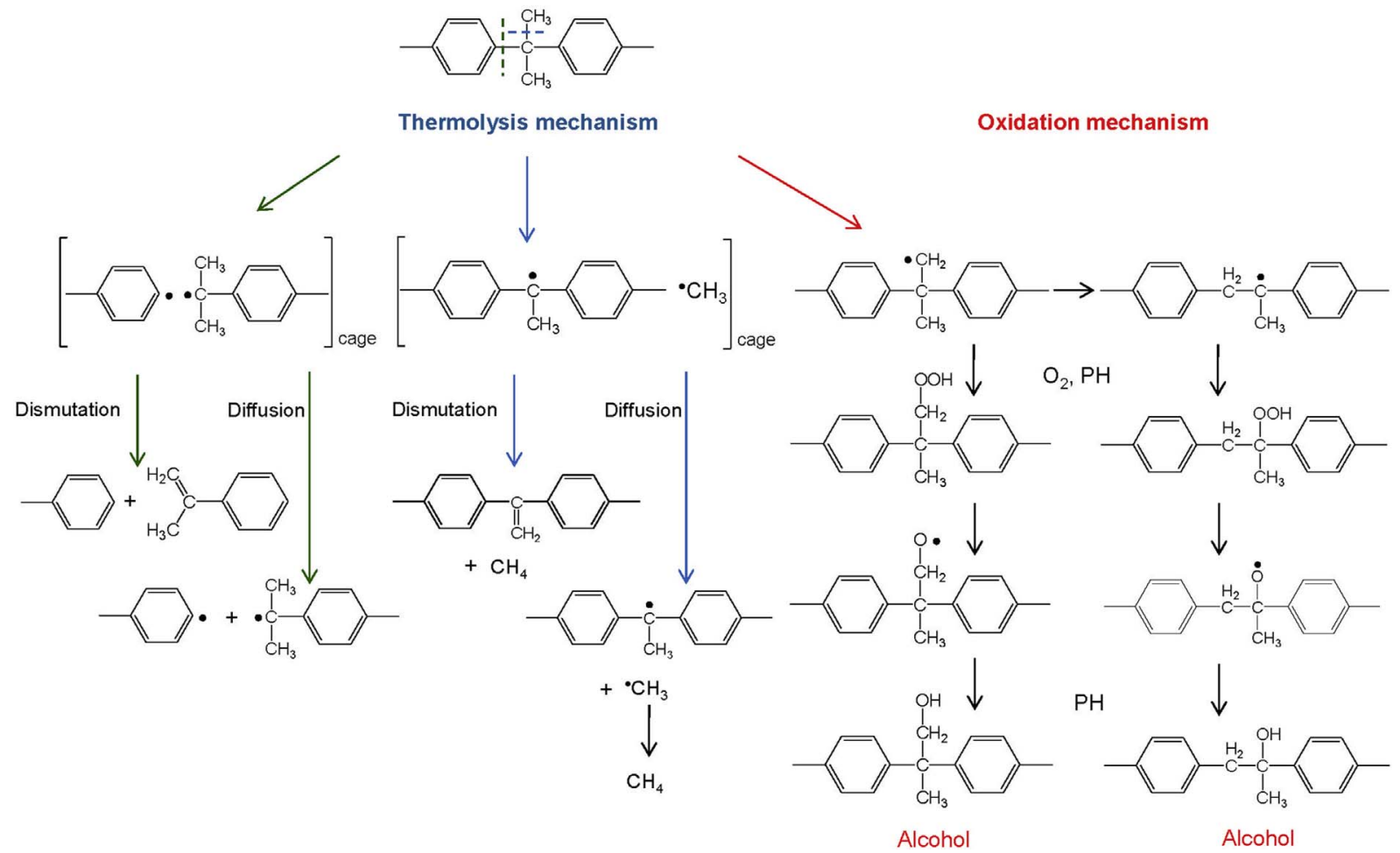

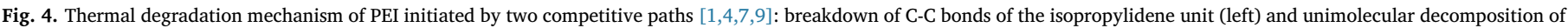
hydroperoxides (right).

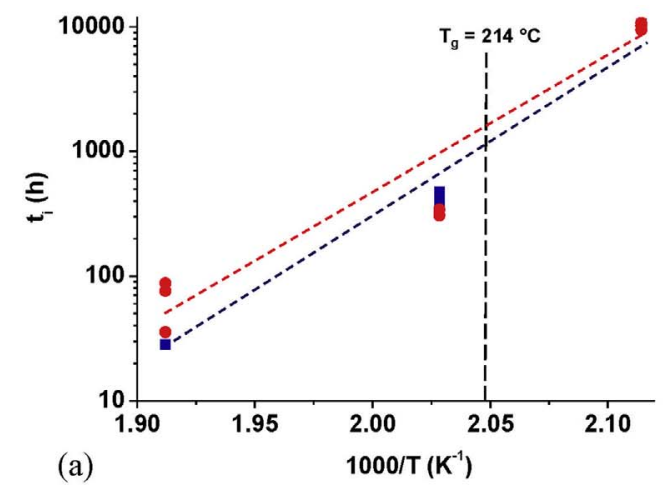

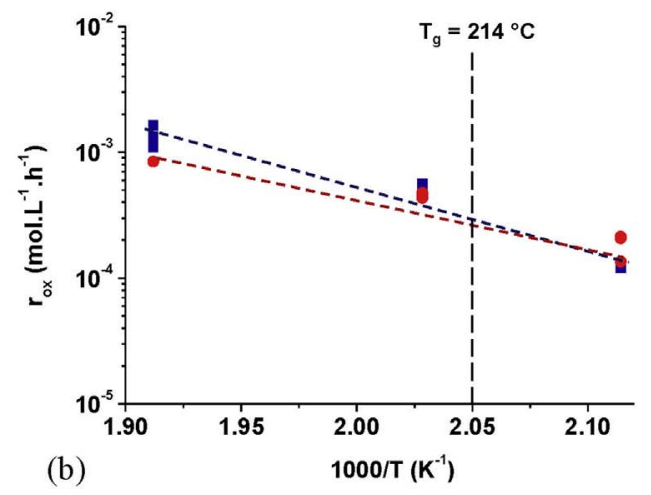

Fig. 5. Arrhenius diagram of the induction times (a) and the maximum rates (b) of the disappearance of C-H bonds $(\square)$ and the accumulation of alcohols ( ) in air between 200 and $250{ }^{\circ} \mathrm{C}$.
Table 1

Activation energy of the induction times $\left(t_{i}\right)$ and the maximum rates $\left(r_{o x}\right)$ of the disappearance of $\mathrm{C}-\mathrm{H}$ bonds and the accumulation of alcohols in air between 200 and $250{ }^{\circ} \mathrm{C}$.

\begin{tabular}{lll}
\hline Groups & $\mathrm{E}_{\mathrm{a}}$ of $\mathrm{t}_{\mathrm{i}}\left(\mathrm{kJ} \cdot \mathrm{mol}^{-1}\right)$ in air & $\mathrm{E}_{\mathrm{a}}$ of $\mathrm{r}_{\mathrm{ox}}\left(\mathrm{kJ} \cdot \mathrm{mol}^{-1}\right)$ in air \\
\hline C-H bonds & 254 & 96 \\
O-H bonds (alcohols) & 204 & 67 \\
\hline
\end{tabular}

centered at $3350 \mathrm{~cm}^{-1}$ and attributed to the elongation vibration of the $\mathrm{O}-\mathrm{H}$ bond of alcohols.

Let us recall that the concentration $\mathrm{C}$ of these various products is related to the absorbance Abs of their IR absorption band according to the Beer-Lambert's law:

$C=\frac{A b s}{e \times \varepsilon}$

where e is the sample thickness (expressed in $\mathrm{cm}$ ) and $\varepsilon$ the coefficient of molar extinction whose averaged values are given in the literature: $\varepsilon(\mathrm{O}-\mathrm{H}$ of alcohols $)=90 \mathrm{~L} \mathrm{~mol}{ }^{-1} \cdot \mathrm{cm}^{-1}[12,13]$ and $\varepsilon(\mathrm{C}-\mathrm{H}$ of $\left.\mathrm{CH}_{3}\right)=42 \mathrm{~L} \mathrm{~mol}^{-1} \cdot \mathrm{cm}^{-1}[14]$.
Consequences of oxidation on the macromolecular architecture of PEI were followed by differential scanning calorimetry (DSC). The DSC thermograms of the PEI films were measured before and after thermal ageing for accessing the changes in the glass transition temperature $\left(\mathrm{T}_{\mathrm{g}}\right)$. The analyzes were carried out with a TA Instruments Q1000 calorimeter between 25 and $300{ }^{\circ} \mathrm{C}$ with a heating rate of $10{ }^{\circ} \mathrm{C} . \mathrm{min}^{-1}$ under a nitrogen flow. The value of $\mathrm{T}_{\mathrm{g}}$ was taken at the inflection point of the variation curve of the heat flux with the temperature.

Finally, the impact of thermal ageing on the elastic properties (in particular, on the Young's modulus) of PEI was determined by microindentation on the polished cross-sections of PEI plates of $3 \mathrm{~mm}$ thickness. The plates were cut in the thickness direction and embedded in a commercial acrylic KM-V resin, which was crosslinked for $12 \mathrm{~h}$ under primary vacuum at room temperature. Then, the plate crosssections were polished with a MECAPOL P320 device using silicon carbide abrasive papers of decreasing particle size (typically from 80 to 2400 granulometry). Finally, a mirror finish was obtained using diamond pastes of decreasing particle size (typically from 3 to $0.25 \mu \mathrm{m}$ ). The indentations were then performed with a CSM Instrument Micro Indenter equipped with a Vickers diamond tip of pyramidal geometry, 

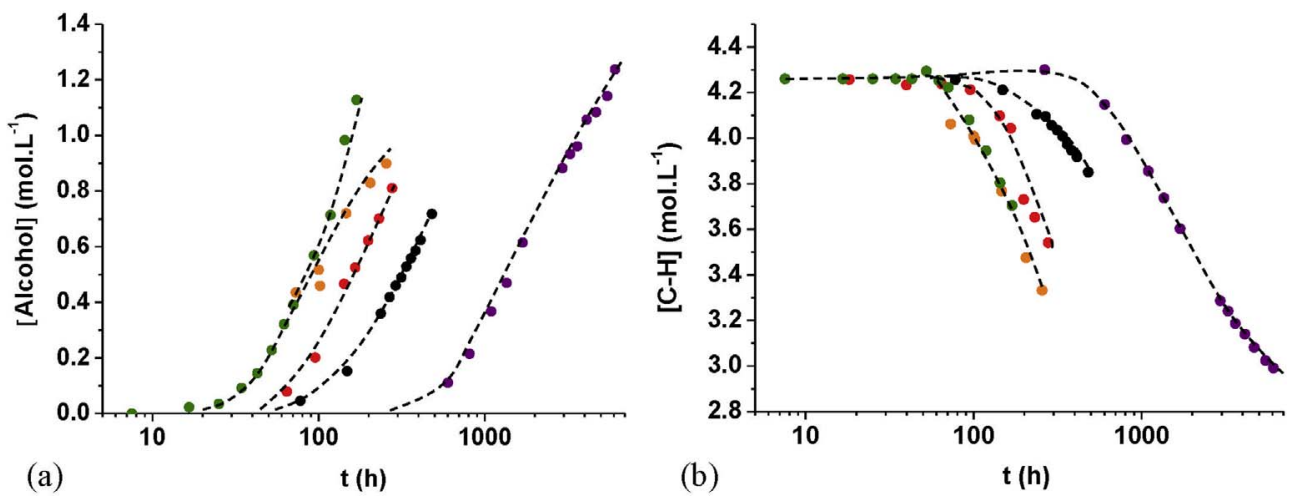

Fig. 6. Changes in the concentration of alcohols (a) and $\mathrm{C}-\mathrm{H}$ bonds (b) during the thermal ageing of PEI under an oxygen pressure of 0.21 bar (in violet), 0.4 bar (black), 1 bar (red), 3 bars (orange) and 5 bars (green) at $220{ }^{\circ} \mathrm{C}$. (For interpretation of the references to colour in this figure legend, the reader is referred to the Web version of this article.)
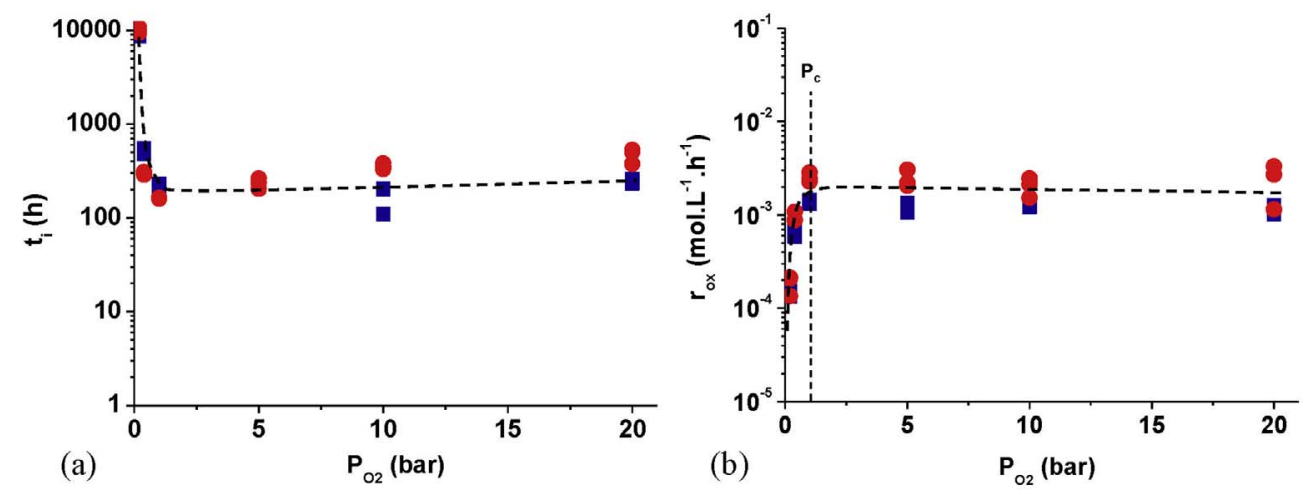

Fig. 7. Changes of the induction times (a) and the maximum rates (b) of the disappearance of $\mathrm{C}-\mathrm{H}$ bonds ( $\square$ ) and the accumulation of alcohols ( with the oxygen partial pressure at $200{ }^{\circ} \mathrm{C}$

Table 2

Critical pressure $\left(\mathrm{P}_{\mathrm{C}}\right)$, induction time $\left(\mathrm{t}_{\mathrm{i}}\right)$ and maximum rate $\left(\mathrm{r}_{\mathrm{ox}}\right)$ of the disappearance of $\mathrm{C}-\mathrm{H}$ bonds or the accumulation of alcohols in oxygen excess at 180,200 and $220^{\circ} \mathrm{C}$.

\begin{tabular}{llll}
\hline Temperature $\left({ }^{\circ} \mathrm{C}\right)$ & $\mathrm{P}_{\mathrm{C}}(\mathrm{bar})$ & $\mathrm{t}_{\mathrm{i}}$ in $\mathrm{O}_{2}$ excess $(\mathrm{h})$ & $\mathrm{r}_{\mathrm{ox}}$ in $\mathrm{O}_{2}$ excess $\left(\mathrm{mol} . \mathrm{L}^{-1} \cdot \mathrm{h}^{-1}\right)$ \\
\hline 180 & $\leq 20$ & 1519 & $0.59 \times 10^{-3}$ \\
200 & 1 & 257 & $1.8 \times 10^{-3}$ \\
220 & 0.6 & 53 & $4.3 \times 10^{-3}$ \\
\hline
\end{tabular}

with a force of $500 \mathrm{mN}$ and a loading and unloading rate of $1000 \mu \mathrm{m} \mathrm{min}^{-1}$. A pause of $5 \mathrm{~s}$ was systematically applied between the loading and unloading. The Indentation 4.37 operating software gives directly the value of the reduced modulus $\mathrm{E}_{\mathrm{r}}$ of the material, which is calculated according to Oliver \& Pharr's method [3,15-17]:

$E_{r}=\frac{\sqrt{\pi} S}{2 \beta \sqrt{A_{c}}}$

where $S$ is the initial slope of the unloading curve, $\beta$ is a shape factor depending on the indenter type ( $\beta=1.012$ for a Vickers tip) and $A_{c}$ is the contact area, between the indenter and the sample, projected perpendicularly to the indenter axis on the sample surface: $A_{C}=a^{2}$, a being the side length of the projected square. This latter quantity is also directly given by the operating software. It depends both on the penetration depth of the indenter and the indenter geometry.

Then, the local elastic modulus $\mathrm{E}$ was determined from the reduced modulus $\mathrm{E}_{\mathrm{r}}$ with the following equation:

$E=\frac{1}{\frac{1-\nu^{2}}{E_{r}}-\frac{1-\nu_{i} 2}{E_{i}}}$

where $\nu$ is the Poisson's coefficient of the virgin PEI: $\nu=0.44$ (supplier data), and $\nu_{i}$ and $E_{i}$ are respectively the Poisson's coefficient and Young's modulus of the diamond indenter: $\nu_{\mathrm{i}}=0.07$ and $\mathrm{E}_{\mathrm{i}}=1141 \mathrm{GPa}$.

The global elastic modulus $\mathrm{E}_{\mathrm{S}}$ is the average value of the $\mathrm{N}$ local values $\mathrm{E}(\mathrm{j})$ constituting the micro-indentation profile:

$E_{S}=\frac{1}{N} \sum_{j=1}^{N} E(j)$

In this study, $E_{S}$ was used as the Young's modulus of the sample after
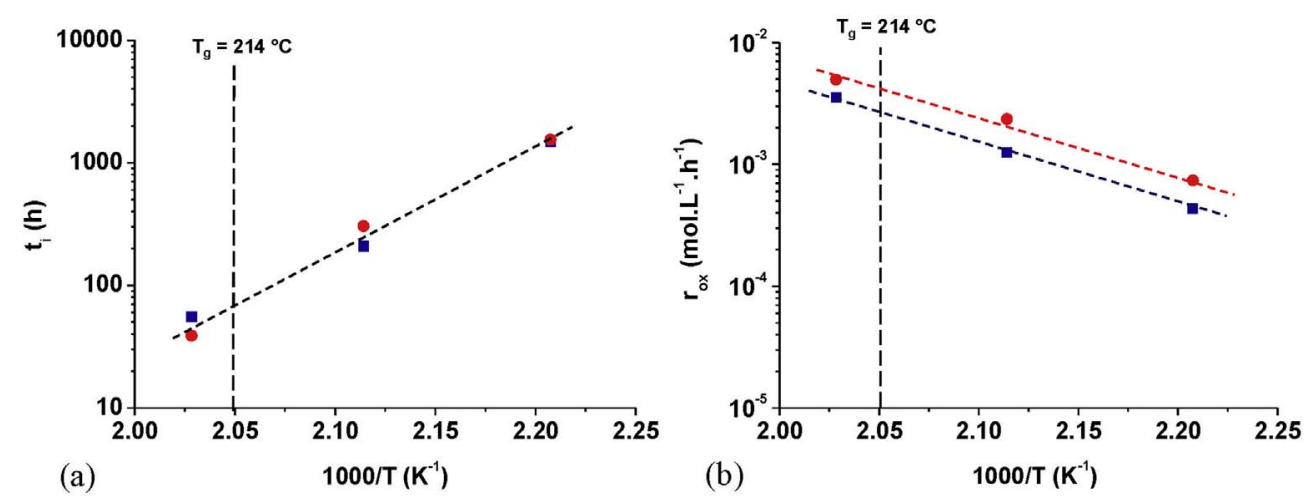

Fig. 8. Arrhenius diagram of the induction times (a) and the maximum rates (b) of the disappearance of $\mathrm{C}-\mathrm{H}$ bonds $(\square)$ and the formation of alcohols ( $)$ in oxygen excess between 180 and $220{ }^{\circ} \mathrm{C}$. 
Table 3

Activation energy of the induction times $\left(t_{i}\right)$ and the maximum rates $\left(r_{o x}\right)$ of the disappearance of $\mathrm{C}-\mathrm{H}$ bonds and the formation of alcohols in oxygen excess between 180 and $220{ }^{\circ} \mathrm{C}$.

\begin{tabular}{lll}
\hline Groups & $\begin{array}{l}\mathrm{E}_{\mathrm{a}} \text { of } \mathrm{t}_{\mathrm{i}}\left(\mathrm{kJ} \cdot \mathrm{mol}^{-1}\right) \text { in } \mathrm{O}_{2} \\
\text { excess }\end{array}$ & $\begin{array}{l}\mathrm{E}_{\mathrm{a}} \text { of } \mathrm{r}_{\mathrm{ox}}\left(\mathrm{kJ}_{\mathrm{mol}}^{-1}\right) \text { in } \mathrm{O}_{2} \\
\text { excess }\end{array}$ \\
\hline C-H bonds & 153 & 97 \\
O-H bonds (alcohols) & 171 & 89 \\
\hline
\end{tabular}

having checked, by uniaxial tensile testing, that it gives a very good estimate of this latter. Indeed, it has been found that their respective values differ only by a factor of 0.7 .

\section{Results and discussion}

\subsection{Changes in molecular structure}

Fig. 2 reports the changes in the concentration of alcohols (at $\left.3345 \mathrm{~cm}^{-1}\right)$ and $\mathrm{C}-\mathrm{H}$ bonds $\left(2970 \mathrm{~cm}^{-1}\right)$ during the thermal ageing of PEI in air between 200 and $250{ }^{\circ} \mathrm{C}$. As expected, the temperature significantly accelerates the oxidation kinetics of PEI.

The consumption of $\mathrm{C}-\mathrm{H}$ bonds is explained both by the release (in the form of methane) of $\mathrm{CH}_{3}$ groups from the isopropylidene unit due to the thermolytic cleavage of the $\mathrm{C}-\mathrm{CH}_{3}$ bonds $[1,6-8]$, but also by the preferential propagation of oxidation on the $\mathrm{CH}_{3}$ groups. Indeed, let us recall that the dissociation energy of a C-H bond is much lower in a $\mathrm{CH}_{3}$ group $\left(\approx 414 \mathrm{~kJ} \mathrm{~mol}^{-1}\right)$ than in an aromatic ring $\left(\approx 465 \mathrm{~kJ} \mathrm{~mol}^{-1}\right)$. In addition, the $\mathrm{C}-\mathrm{H}$ bond is even more labile when the $\mathrm{CH}_{3}$ group is located near a double bond or an aromatic ring. As an example, in the case of toluene, its dissociation energy is only $347 \mathrm{~kJ} \mathrm{~mol}^{-1}$ [18].

As an example, Fig. 3 compares the changes in the concentration of alcohols and C- $\mathrm{H}$ bonds in air at $220{ }^{\circ} \mathrm{C}$. It is found that alcohols appear as soon as $\mathrm{C}-\mathrm{H}$ bonds begin to disappear. More generally, the changes in these two species are perfectly correlated: the rates (of accumulation or disappearance) become maximum then slow down suddenly, to finally tend towards a quasi-constant value, after the same exposure durations. This result confirms that alcohols are formed by oxidation of the $\mathrm{CH}_{3}$ groups as already described in the literature for polymers containing the bisphenol A unit in their chemical structure, in particular for PEI and polycarbonate (PC) $[1,4]$.

In addition, the initial presence of an induction period on all the kinetic curves clearly indicates that the thermolysis of the isopropylidene unit is not the main initiation mechanism between 200 and $250{ }^{\circ} \mathrm{C}$. Indeed, according to literature [19], we are rather in the case of a thermal oxidation mechanism initiated by its main propagation product: the hydroperoxide group $\mathrm{POOH}$. Such a "closed loop" mechanism allows explaining why, during a more or less long induction period (depending both on the chemical structure of polymer and the agressiveness of ageing conditions), oxidation is not detectable by common spectrochemical techniques, but also why, at the end of this induction
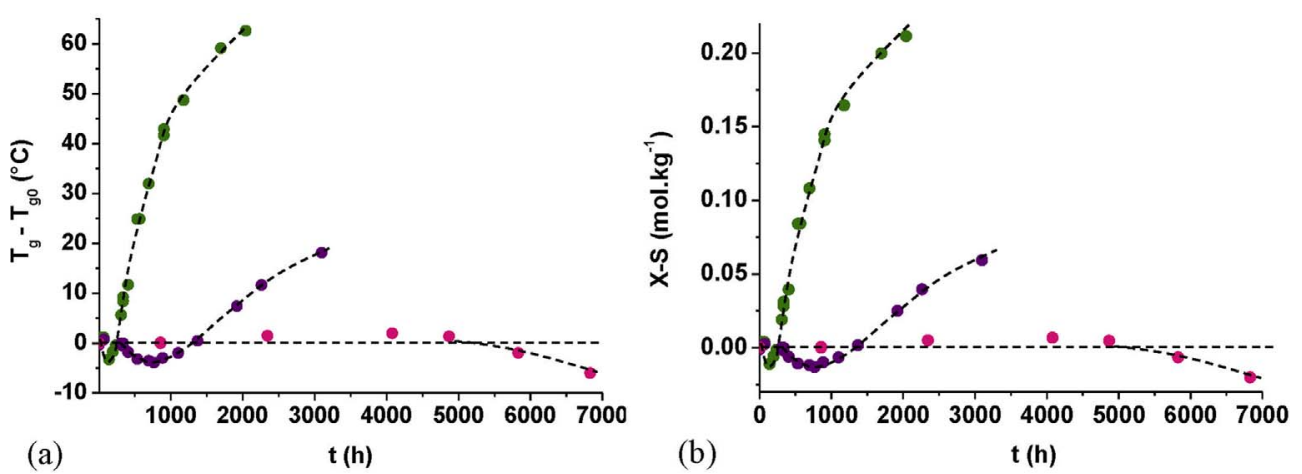

Fig. 9. Differences between the glass transition temperature and its initial value $\left(\mathrm{T}_{\mathrm{g}}-\mathrm{T}_{\mathrm{g} 0}\right)$ (a) and between the numbers of crosslinking and chain scission events (X-S) (b) during the thermal ageing of PEI in air at 200 (in pink), 220 (violet) and $250{ }^{\circ} \mathrm{C}$ (green). (For interpretation of the references to colour in this figure legend, the reader is referred to the Web version of this article.) 


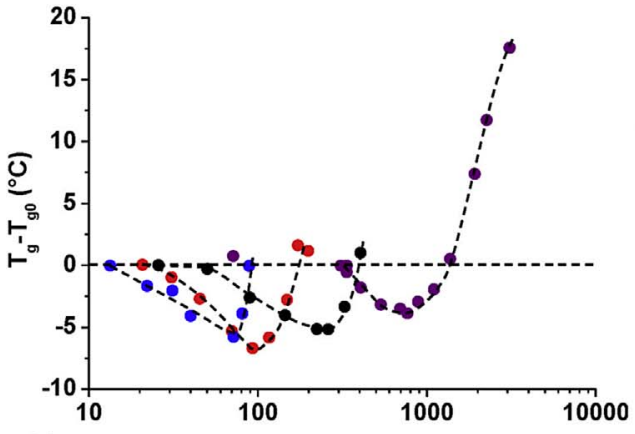

(a)

t (h)
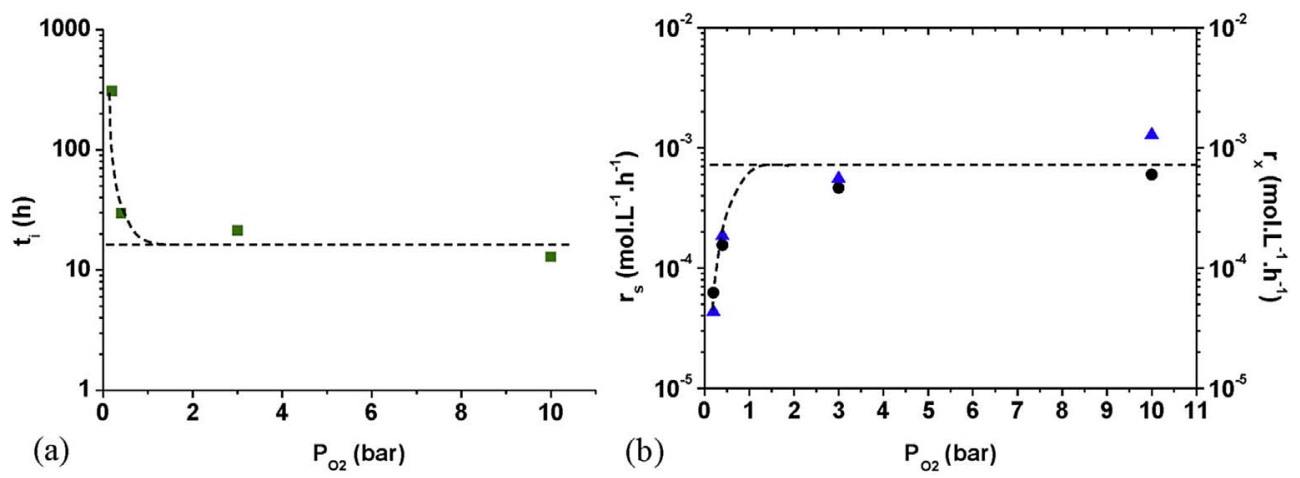

Fig. 10. Differences between the glass transition temperature and its initial value $\left(\mathrm{T}_{\mathrm{g}}-\mathrm{T}_{\mathrm{g} 0}\right)$ (a) and between the numbers of crosslinking and chain scission events (X-S) (b) during the thermal ageing of PEI under an oxygen pressure of 0.21 bar (in violet), 0.4 bar (black), 3 bars (red) and 10 bars (blue) at $220^{\circ} \mathrm{C}$. (For interpretation of the references to colour in this figure legend, the reader is referred to the Web version of this article.)

Fig. 11. Changes in the induction time of macromolecular modifications and the maximum rates of chain scission $(\boldsymbol{\bullet})$ and crosslinking $(\boldsymbol{A})$ with oxygen partial pressure at $220{ }^{\circ} \mathrm{C}$.
Table 4

Critical pressure $\left(\mathrm{P}_{\mathrm{c}}\right)$, induction time $\left(\mathrm{t}_{\mathrm{i}}\right)$ and maximum rate $(\mathrm{r})$ for molar and macromolecular modifications in oxygen excess at $220^{\circ} \mathrm{C}$.

\begin{tabular}{|c|c|c|c|}
\hline & $\mathrm{P}_{\mathrm{c}}$ (bar) & $\begin{array}{l}t_{i} \text { in } O_{2} \text { excess } \\
\text { (h) }\end{array}$ & $\begin{array}{l}\mathrm{r} \text { in } \mathrm{O}_{2} \text { excess } \\
\left(\mathrm{mol} \cdot \mathrm{L}^{-1} \cdot \mathrm{h}^{-1}\right)\end{array}$ \\
\hline Degradation products & 0.6 & 53 & $4.3 \times 10^{-3}$ \\
\hline Chain scissions & 3 & 17 & $5.3 \times 10^{-4}$ \\
\hline Crosslinking & 3 & - & $9.2 \times 10^{-4}$ \\
\hline
\end{tabular}

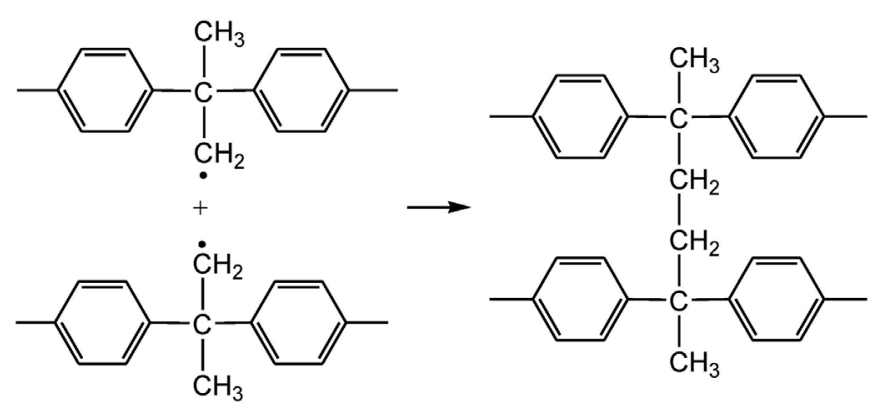

Fig. 12. Termination by coupling of $P$ radicals leading to the formation of a C-C bridge between two macromolecular chains and thus, to a crosslinking node.

between 180 and $220{ }^{\circ} \mathrm{C}$ (see Table 2). The corresponding activation energies are given in Table 3. It can be seen that they are very similar for the two chemical species under consideration. As expected, for an oxidation reaction mainly initiated by the unimolecular decomposition of hydroperoxides, the activation energy of $t_{i}$ is higher than $140 \mathrm{~kJ} \mathrm{~mol}^{-1}$, but not so much higher [21]. In comparison, for a bimolecular decomposition, this value would have been appreciably lower: typically $\mathrm{E}_{\mathrm{a}}=100-110 \mathrm{~kJ} \mathrm{~mol}^{-1}[22,23]$.

In addition, the activation energy of $\mathrm{r}_{\mathrm{ox}}$ is located in the low range of the values usually reported in the literature for hydrocarbon polymers. Indeed, for a moderately oxidizable polymer such as $\mathrm{PE}, \mathrm{E}_{\mathrm{a}}$ is quite high: $\mathrm{E}_{\mathrm{a}} \approx 138 \mathrm{~kJ} \mathrm{~mol}^{-1}$ [22]. In contrast, for highly oxidizable polymers such as PP or unsaturated elastomers, $\mathrm{E}_{\mathrm{a}}$ is significantly lower: $\mathrm{E}_{\mathrm{a}} \approx 92 \mathrm{~kJ} \mathrm{~mol}^{-1}$ for PP [23] and $\mathrm{E}_{\mathrm{a}} \approx 84 \mathrm{~kJ} \mathrm{~mol}^{-1}$ for HTPB [24]. As feared, the presence of aromatic rings in the vicinity of the $\mathrm{CH}_{3}$ groups greatly increases the oxidation sensitivity of these latter.

Finally, let us notice that the activation energies of $t_{i}$ and $r_{o x}$ take different values in oxygen default (for instance in air, see Table 1) due to the temperature dependence of the critical pressure $\mathrm{P}_{\mathrm{C}}$.

\subsection{Changes in macromolecular structure}

The molecular mass is the structural variable commonly used for monitoring the changes in the macromolecular architecture of the polymer, i.e. chain scissions (denoted S) and crosslinking events (denoted X), during its chemical ageing. As each chain scission leads to a chain formation, whereas each crosslinking event leads to a chain disppearance, it can be written:

$S-X=\frac{1}{M_{n}}-\frac{1}{M_{n 0}}$

where $M_{n 0}$ and $M_{n}$ are the number average molecular masses before and after ageing respectively.

However, in this study, it was impossible to measure directly the molecular mass of PEI after thermal ageing by a classical chromatographic (CES or GPC) or viscometric (in solution) method, because this polymer crosslinks and thus, becomes rapidly insoluble in its usual solvents, e.g. in dichloromethane [25] and dimethylacetamide [26]. It was thus necessary to use an indirect method having already proved its worth for other aromatic polymers, for instance PEEK [27]: differential scanning calorimetry (DSC). Indeed, DSC gives access to the value of $M_{n}$ if knowing the value of $\mathrm{T}_{\mathrm{g}}$ and applying the Fox-Flory's relationship [28]:

$T_{g}-T_{g 0}=-k_{F F}\left(\frac{1}{M_{n}}-\frac{1}{M_{n 0}}\right)$

where $\mathrm{k}_{\mathrm{FF}}$ is the Fox-Flory's constant (expressed in K.mol.kg ${ }^{-1}$ ), which 


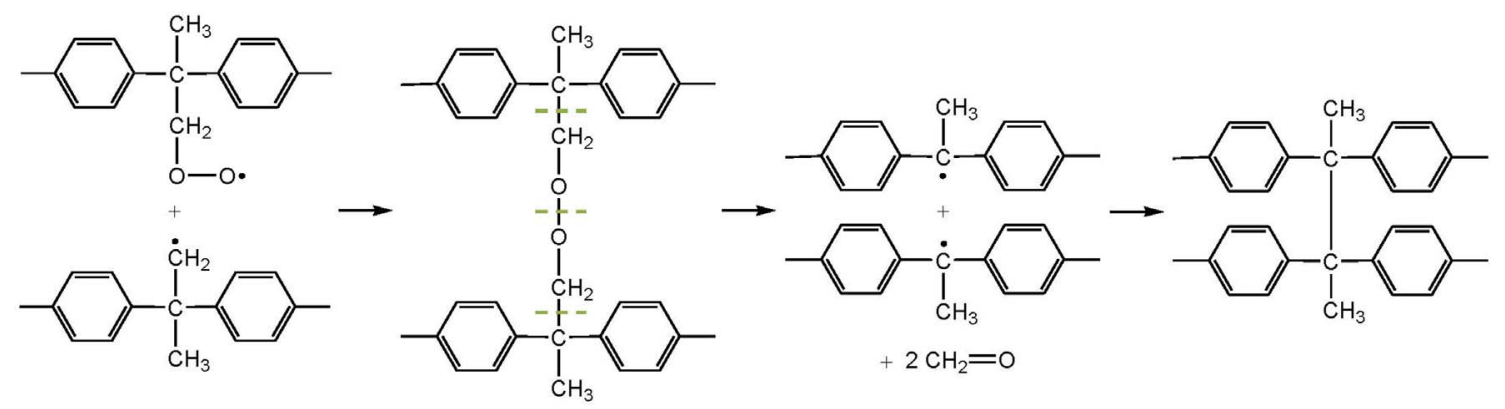

Fig. 13. Termination by coupling of $\mathrm{P}^{\cdot}$ et $\mathrm{PO}_{2} \cdot$ radicals leading to the formation of a C-C bridge between two macromolecular chains and thus, to a crosslinking node.

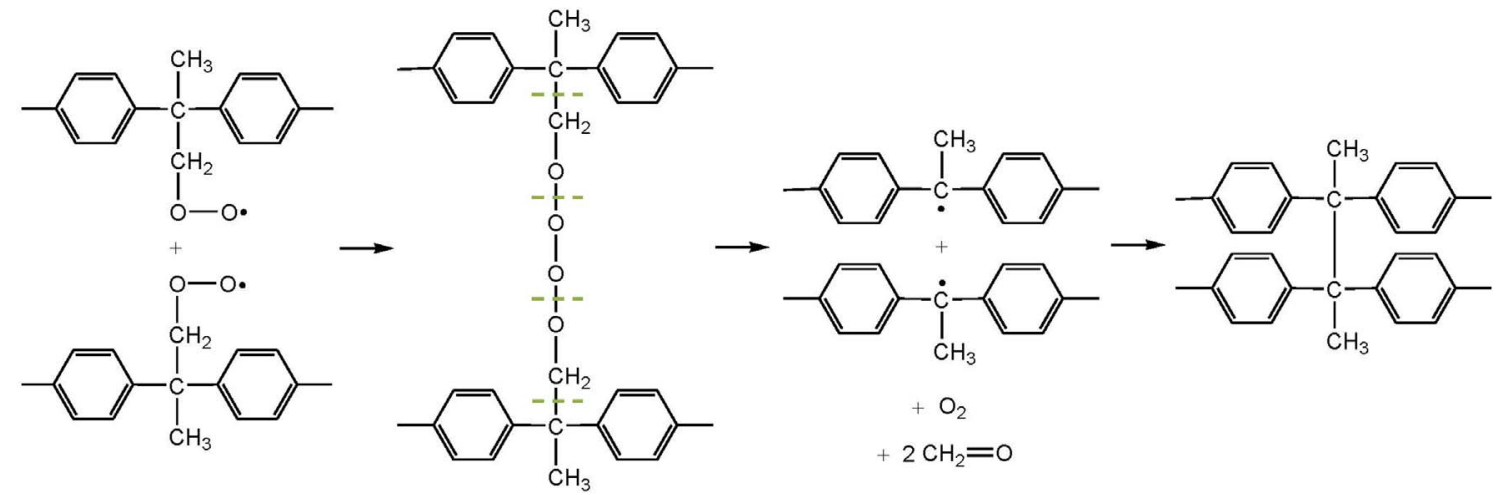

Fig. 14. Termination by coupling of $\mathrm{PO}_{2} \cdot$ radicals leading to the formation of a C-C bridge between two macromolecular chains and thus, to a crosslinking node.

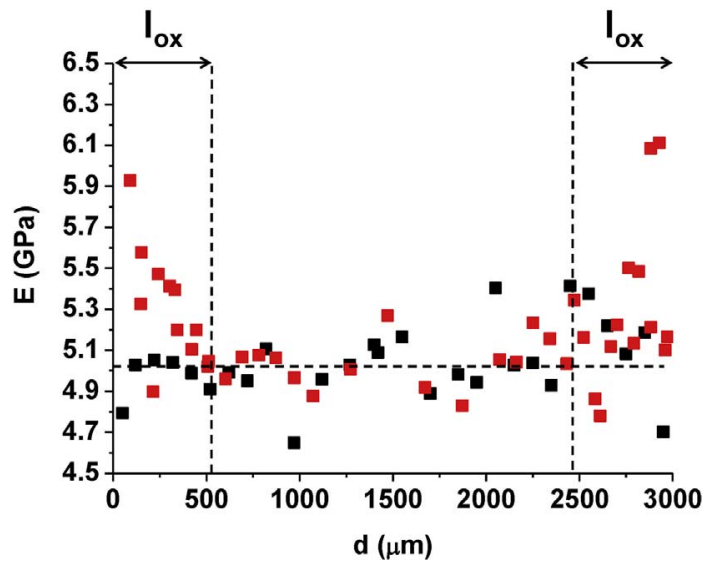

Fig. 15. Profile of the Young's modulus in the thickness of the PEI plate before (in black) and after (red) $1966 \mathrm{~h}$ of exposure in air at $250^{\circ} \mathrm{C}$. (For interpretation of the references to colour in this figure legend, the reader is referred to the Web version of this article.)

is an increasing function of the chain stiffness.

$\mathrm{k}_{\mathrm{FF}}$ was determined by three different methods: the Bicerano's relationship [29], the free volume theory $[27,30]$ and the copolymer theory [27]. Its average value is: $\mathrm{k}_{\mathrm{FF}}=295 \pm 85 \mathrm{~K} \mathrm{~kg} \mathrm{~mol}^{-1}$.

By combining Eq. (5) and Eq. (6), the following relationship was obtained between $\mathrm{T}_{\mathrm{g}}$ and the numbers of chain scissions and crosslinking events:

$T_{g}-T_{g 0}=k_{F F}(X-S)$

It can be seen that $\mathrm{T}_{\mathrm{g}}$ decreases with the number of chain scissions, but increases with the number of crosslinking events.

Fig. 9 reports the differences between $\mathrm{T}_{g}$ and its initial value $\left(\mathrm{T}_{g}\right.$ $\mathrm{T}_{\mathrm{g} 0}$ ) and between the numbers of crosslinking and chain scission events (X - S) for PEI films exposed in air between 200 and $250{ }^{\circ} \mathrm{C}$. At 220 and $250{ }^{\circ} \mathrm{C}$, two successive behaviors are clearly distinguished: first of all, an initial decrease in $\mathrm{T}_{\mathrm{g}}$ which reflects a relative predominance of chain scissions over crosslinking in the early periods of exposure; then, a strong increase in $\mathrm{T}_{g}$ beyond its initial value, indicating that crosslinking becomes in turn predominant. These two phenomena (chain scissions and crosslinking) are highly thermo-activated. At $200{ }^{\circ} \mathrm{C}$, it is suspected that this scenario is still valid, but it will only occur after a (long) induction period of about $5000 \mathrm{~h}$.

DSC analyzes were also carried out on PEI films after thermal ageing at $220{ }^{\circ} \mathrm{C}$ under different oxygen partial pressures ranged between 0.21 and 10 bars. The changes in $\left(\mathrm{T}_{\mathrm{g}}-\mathrm{T}_{\mathrm{g} 0}\right)$ and $(\mathrm{X}-\mathrm{S})$ are given in Fig. 10. It is found the same behavior as in air. However, the initial fall of $T_{g}$ is accentuated when increasing the oxygen partial pressure. In a general way, the oxygen partial pressure accelerates the kinetics of chain scissions and crosslinking up to a critical pressure of about 0.6 bar at $220{ }^{\circ} \mathrm{C}$, a value which has been already determined, but with a better accuracy, by FTIR spectrophotometry. It is noteworthy that it was difficult to follow the PEI crosslinking above its initial value of $T_{g}$, in particular under high oxygen partial pressure, due to the extreme brittleness of the PEI films.

The values of the induction time $\left(t_{i}\right)$ of macromolecular modifications and the maximum rates of chain scission $\left(r_{S}\right)$ and crosslinking $\left(r_{X}\right)$ determined at $220{ }^{\circ} \mathrm{C}$ were plotted as a function of the oxygen partial pressure in Fig. 11. It can be seen that the values of $r_{S}$ and $r_{X}$ are comparable. In addition, the curves exhibit a hyperbolic shape and reach a plateau, which is a characteristic of the oxygen excess regime, above $\mathrm{P}_{\mathrm{C}}=3$ bars. The values of $\mathrm{t}_{\mathrm{i}}, \mathrm{r}_{\mathrm{S}}$ and $\mathrm{r}_{\mathrm{X}}$ in oxygen excess at $220{ }^{\circ} \mathrm{C}$ are summarized in Table 4 where they are compared to the values obtained for the degradation products.

In Table 4, it can be seen that chain scissions are detected well before the disappearance of the $\mathrm{CH}_{3}$ groups and the formation of alcohols, whatever the oxygen partial pressure. Thus, it can be deduced that they occur predominantly at the $\mathrm{Ph}-\mathrm{C}\left(\mathrm{CH}_{3}\right)_{2}$ bonds in the initiation stages by thermolysis, but also by unimolecular decomposition of hydroperoxides (in particular, during the rearrangement by $\beta$ scission of alkoxy radicals $\mathrm{PO}^{\circ}$ ). Let us recall that this last reaction is in competition with the hydrogen abstraction leading to the formation of alcohols (Fig. 4). 


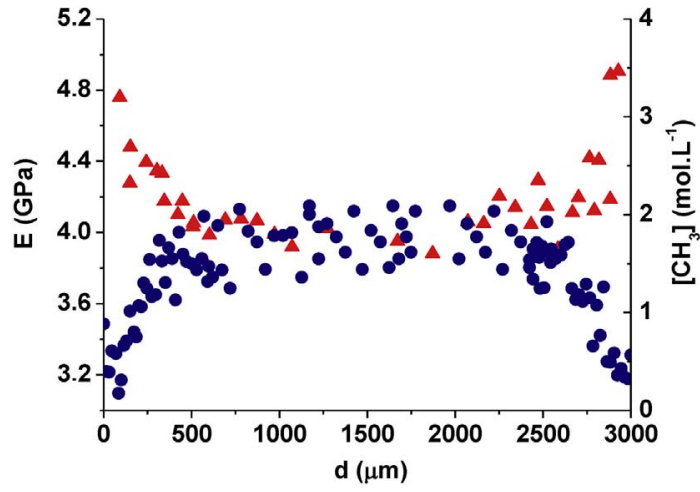

Fig. 16. Comparison of the degradation profiles determined throughout the thickness of a PEI plate by FTIR spectrophotometry (•) and micro-indentation ( $\mathbf{A})$ after $1966 \mathrm{~h}$ of exposure in air at $250{ }^{\circ} \mathrm{C}$.

\section{$429 \mathrm{~h}$}

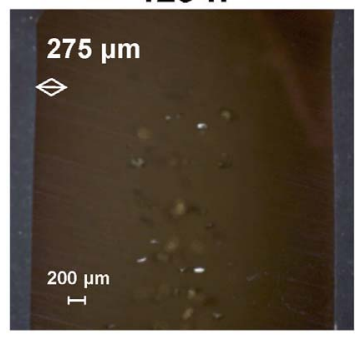

\section{$1270 \mathrm{~h}$}

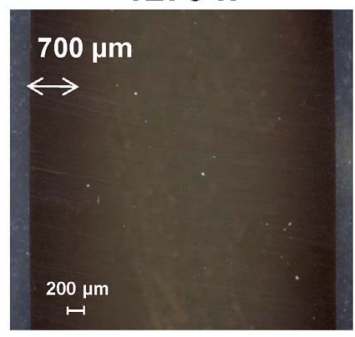

Fig. 17. Examination by optical microscopy (with a magnification of $\times 2,5$ ) of the superficial oxidized layer of PEI after different durations of exposure in air at $220^{\circ} \mathrm{C}$.

Table 5

Average thickness of oxidized layer of PEI determined by micro-indentation, FTIR spectrophotometry or optical microscopy after different durations of exposure in air at 220 and $250{ }^{\circ} \mathrm{C}$

\begin{tabular}{lll}
\hline $\mathrm{T}\left({ }^{\circ} \mathrm{C}\right)$ & $\mathrm{t}(\mathrm{h})$ & $\mathrm{l}_{\mathrm{ox}}(\mu \mathrm{m})$ \\
\hline 220 & 429 & $275 \pm 25$ \\
& 667 & $400 \pm 50$ \\
& 1270 & $750 \pm 50$ \\
& 1985 & $750 \pm 50$ \\
250 & 94 & $225 \pm 25$ \\
& 670 & $350 \pm 75$ \\
& 1273 & $490 \pm 60$ \\
& 1966 & $550 \pm 50$ \\
\hline
\end{tabular}

Concerning crosslinking, it becomes predominant over chain scissions after a longer exposure duration $\left(800 \mathrm{~h}\right.$ at $220^{\circ} \mathrm{C}$ in air), i.e. when a sufficient quantity of alkyl $\mathrm{P}^{\circ}$ and peroxyl $\mathrm{PO}_{2}{ }^{\circ}$ radicals has been formed. It can thus be concluded that it results from the coupling of these radicals, as already proposed in the literature for PC [3]. Examples of potential mechanisms of crosslinking for PEI are presented in Figs. 12-14. They all lead to a C-C bridge between two macromolecular chains. In the absence of oxygen, crosslinking could directly result from the coupling of primary $\mathrm{P}^{*}$ radicals (Fig. 12). In oxygen default, as dialkyl peroxide bridges POOP cannot survive at the temperatures under study (typically for $\mathrm{T} \geq 180{ }^{\circ} \mathrm{C}$ ), they decompose almost instantaneously to form two $\mathrm{PO}^{\circ}$ radicals which can rearrange in different ways and, in particular, into tertiary $\mathrm{P}^{*}$ radicals by $\beta$ scission (Fig. 13). These latter could then couple to form a crosslink node. The same reaction pathway could be proposed in oxygen excess, just after the rapid decomposition of the very unstable tetraoxide bridges POOOOP (Fig. 14).

Finally, it can be noticed that the macromolecular modifications are considerably slower than the disappearance of $\mathrm{CH}_{3}$ groups or the formation of alcohols (see Table 4).

\subsection{Consequences of oxidation on the elastic properties}

The profiles of elastic modulus generated by oxidation in the thickness of PEI plates were determined by micro-indentation. As an example, the profiles obtained before and after $1966 \mathrm{~h}$ of exposure in air at $250{ }^{\circ} \mathrm{C}$ are reported in Fig. 15. As expected, the initial profile is almost flat. The corresponding average value $\mathrm{E}_{\mathrm{S}}$ of the elastic modulus is $5.0 \pm 0.2 \mathrm{GPa}$. It is barely higher than the value of the Young's modulus determined by uniaxial tensile testing on dumbbell specimens: $3.5 \pm 0.1 \mathrm{GPa}$. For this reason, in the present study, a correction factor of 0.7 has systematically been applied to the indentation modulus in order to access the value of the Young's modulus.

During thermal ageing, an increase in Young's modulus is observed in the superficial oxidized layer (Fig. 15). This increase correlates perfectly with the disappearance of $\mathrm{CH}_{3}$ groups determined by FTIR spectrophotometry in an ATR mode (Fig. 16). In addition, the thicknesses of oxidized layer determined with these two techniques (i.e. micro-indentation and FTIR spectrophotometry) are comparable. They are of the same order of magnitude as the thicknesses of the brownish layer observed by optical microscopy on the free edges of the samples. As an example, Fig. 17 shows the micrographs obtained after four different times of exposure in air at $220^{\circ} \mathrm{C}$. It is clear that oxidation results in a browning of PEI.

The average values of the thickness of oxidized layer determined in air at 220 and $250{ }^{\circ} \mathrm{C}$ with these three techniques are summarized in Table 5 .

However, the increase in Young's modulus is not a direct consequence of oxidation but, above all, of a physical ageing revealed by the appearance and growth of an endotherm of enthalpic relaxation (or structural relaxation) within the glass transition zone in the DSC thermograms (Fig. 18).

Thus, if PEI is initially in a glassy state (case of thermal ageings at 180 and $200{ }^{\circ} \mathrm{C}$ ), the increase in Young's modulus is detected from the early periods of exposure. In contrast, if PEI is initially in a rubbery state (case of thermal ageings at 220 and $250{ }^{\circ} \mathrm{C}$ ), the Young's modulus increase is detected only when $\mathrm{T}_{\mathrm{g}}$ becomes higher than the exposure

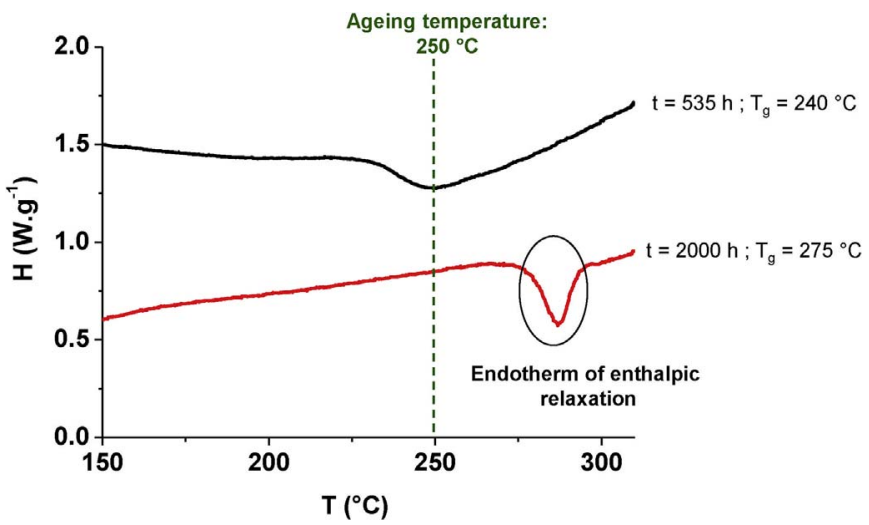

Fig. 18. DSC thermogrammes of PEI films after $535 \mathrm{~h}$ and $2000 \mathrm{~h}$ of exposure in air at $250{ }^{\circ} \mathrm{C}$. 

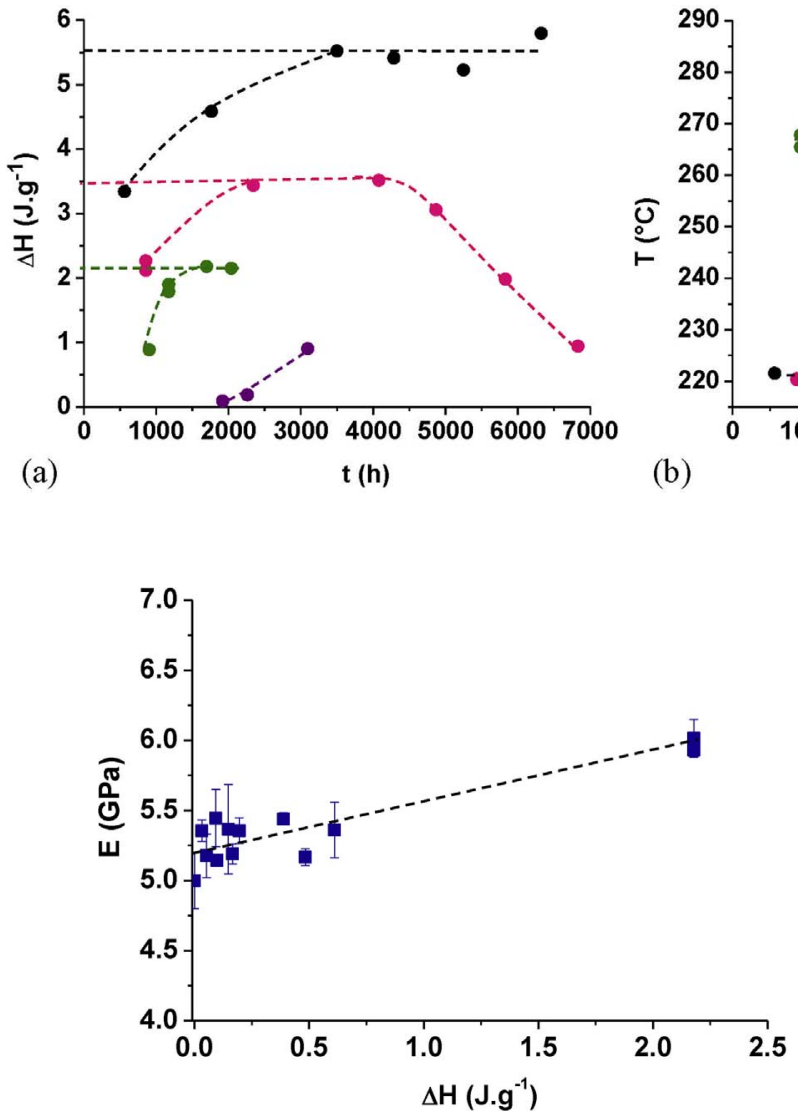

Fig. 20. Local changes in the Young's modulus with the relaxation enthalpy during the thermal ageing of PEI in air at 220 and $250{ }^{\circ} \mathrm{C}$.

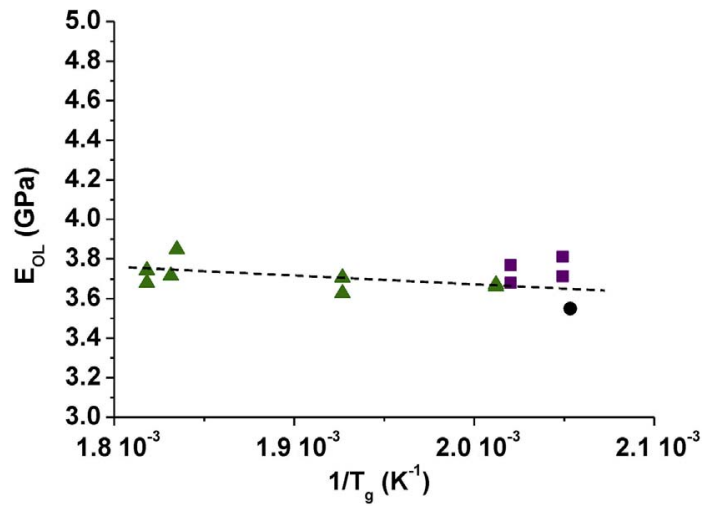

Fig. 21. Changes in the Young's modulus of the oxidized layer of PEI plates in fonction of its reciprocal $\mathrm{T}_{\mathrm{g}}$ before $(\boldsymbol{\bullet})$ and after exposure in air at $220(\boldsymbol{\square})$ and $250{ }^{\circ} \mathrm{C}(\boldsymbol{\Delta})$.

temperature, typically after $225 \mathrm{~h}$ of exposure in air at $220^{\circ} \mathrm{C}$ and after $1250 \mathrm{~h}$ of exposure in air at $250{ }^{\circ} \mathrm{C}$.

Fig. 19 shows the changes in the enthalpy and the temperature of the endothermic peak during the thermal ageing of PEI in air between 180 and $250{ }^{\circ} \mathrm{C}$. These two quantities increase with the exposure time until reaching a thermodynamic equilibrium state at 180 and $250{ }^{\circ} \mathrm{C}$. However, at $200{ }^{\circ} \mathrm{C}$, they decrease at longer term.

(b)
Fig. 19. Changes in the enthalpy (a) and the temperature of the endothermic peak (b) during the thermal ageing of PEI in air at 180 (black), 200 (pink), 220 (violet) and $250{ }^{\circ} \mathrm{C}$ (green). (For interpretation of the references to colour in this figure legend, the reader is referred to the Web version of this article.)

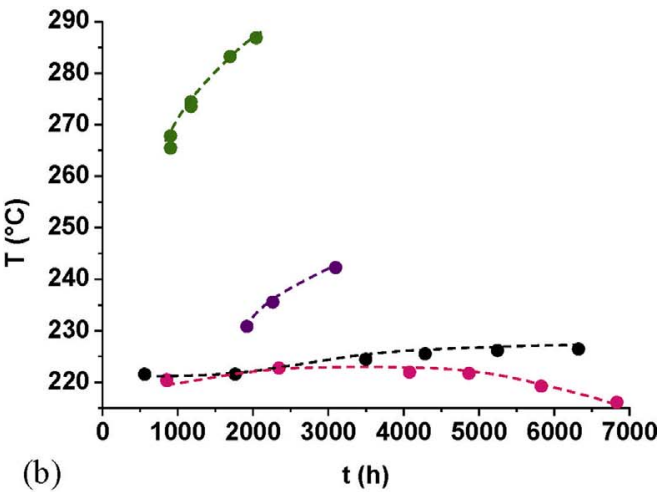

macromolecular structures (by coupling $\mathrm{P}^{\circ}$ and $\mathrm{PO}_{2}{ }^{\circ}$ radicals) reduce also progressively the material ability to undergo a structural relaxation.

On this basis, a correlation was established between the local values of the Young's modulus, determined by micro-indentation before and after exposure of the PEI plates in air at 220 and $250{ }^{\circ} \mathrm{C}$, and the corresponding values of the relaxation enthalpy determined by DSC (Fig. 20). It writes:

$E=5.2+0.35 \times \Delta H$

The average value $\mathrm{E}_{\mathrm{OL}}$ of the Young's modulus of the oxidized layer, for PEI plates aged in air at 220 and $250{ }^{\circ} \mathrm{C}$, was calculated with Eq. (4). These values were plotted as a function of the reciprocal $\mathrm{T}_{\mathrm{g}}$ in Fig. 21. It can be seen that all the points are placed around a single master straight-line whose the equation satisfies the relationship of Gilbert et al. [31]:

$E_{O L}(T)=E(0 K)\left(1-\alpha_{E} \frac{T}{T_{g}}\right)$

where $\mathrm{E}(0 \mathrm{~K})$ is the value of the Young's modulus at $0 \mathrm{~K}$ and $\alpha_{\mathrm{E}}$ is a constant.

Thus, for PEI, it is found: $\mathrm{E}(0 \mathrm{~K})=4.1 \mathrm{GPa}$ and $\alpha_{\mathrm{E}}=0.18$. It is noteworthy that this latter value is of the same order of magnitude as the value $\left(\alpha_{\mathrm{E}}=0.3\right)$ proposed in the literature by Gilbert et al. [31], which would be, according to these authors, almost independent of the polymer structure.

\section{Conclusion}

The thermal degradation of the PEI matrix has been studied in the rubbery state $\left(220\right.$ and $\left.250{ }^{\circ} \mathrm{C}\right)$ and in the glassy state $\left(180\right.$ and $\left.200{ }^{\circ} \mathrm{C}\right)$ under oxygen partial pressures ranged between 0.21 and 50 bars, i.e. in domains of temperature and oxygen partial pressure still totally unexplored. The analysis at the molecular scale, by FTIR spectrophotometry, has allowed confirming the thermolysis and thermo-oxidation mechanisms proposed in the literature involving the $\mathrm{CH}_{3}$ groups of the isopropylidene unit of the bisphenol A part, but also identifying alcohols as the main oxidation products. The analysis at the upper scales, by DSC then micro-indentation, has allowed showing, on the one hand, that chain scissions are majority at the beginning of exposure then crosslinking becomes predominant at longer term, whatever the oxygen partial pressure. On the other hand, the diffusion control of oxidation results in the formation of an oxidized superfical layer in which the elastic properties of PEI are significantly impacted. However, the increase in Young's modulus is not a direct consequence of oxidation, but it is due, above all, to a physical ageing.

In a next communication, a kinetic model will be derived from the oxidation mechanistic scheme established for PEI, and it will be interfaced with the different structure/property relationships (in particular, with Eq. (7) and Eq. (9)) identified in this study. This theoretical tool 
will allow us predicting not only the degradation state of PEI, but also the changes in its thermomechanical properties during the thermal ageing. The validity of this tool will be checked from all the experimental data collected in this study.

\section{References}

[1] S. Carroccio, C. Puglisi, G. Montaudo, New vistas in polymer degradation. Thermal oxidation processes in poly(ether imide), Macromolecules 38 (2005) 6849-6862.

[2] A. Rivaton, Recent advances in bisphenol-A polycarbonate photodegradation, Polym. Degrad. Stab. 49 (1995) 163-179.

[3] S. Collin, P.O. Bussière, S. Thérias, J.M. Lambert, J. Perdereau, J.-L. Gardette, Physicochemical and mechanical impacts of photo-ageing on bisphenol a polycarbonate, Polym. Degrad. Stab. 97 (2012) 2284-2293.

[4] A. Rivaton, B. Mailhot, J. Soulestin, H. Varghese, J.-L. Gardette, Comparison of the photochemical and thermal degradation of bisphenol-A polycarbonate and trimethylcyclohexane-polycarbonate, Polym. Degrad. Stab. 75 (2002) 17-33.

[5] S. Kuroda, I. Mita, Degradation of aromatic polymers-II. The crosslinking during thermal and thermo-oxidative degradation of a polyimide, Eur. Polym. J. 25 (1989) 611-620.

[6] M.A. Corres, M. Zubitur, M. Cortazar, A. Múgica, Thermal and thermo-oxidative degradation of poly(hydroxy ether of bisphenol-A) studied by TGA/FTIR and TGA/ MS, J. Anal. Appl. Pyrolysis 92 (2011) 407-416.

[7] S. Carroccio, C. Puglisi, G. Montaudo, Thermal degradation mechanisms of polyetherimide investigated by direct pyrolysis mass spectrometry, Macromol. Chem. Phys. 200 (1999) 2345-2355.

[8] G. Lisa, C. Hamciuc, E. Hamciuc, N. Tudorachi, Thermal and thermo-oxidative stability and probable degradation mechanism of some polyetherimides, J. Anal Appl. Pyrolysis 118 (2016) 144-154.

[9] H. Farong, W. Xueqiu, L. Shijin, The thermal stability of polyetherimide, Polym. Degrad. Stab. 18 (1987) 247-259.

[10] R.A. Dine-Hart, D.B.V. Parker, W.W. Wright, Oxidative degradation of a polyimide film: I. Initial studies, Br. Polym. J. 3 (5) (1971) 222-225.

[11] L. Augh, J.W. Gillespie, B.K. Fink, Degradation of continuous carbon fiber reinforced polyetherimide composites during induction heating, J. Thermoplast. Compos Mater 14 (2001) 96-115.

[12] S. Commereuc, D. Vaillant, J.L. Philippart, J. Lacoste, J. Lemaire, D.J. Carlsson, Photo and thermal decomposition of iPP hydroperoxides, Polym. Degrad. Stab. 57 (1997) 175-182.

[13] D.J. Carlsson, R. Brousseau, D.M. Wiles, Reactions of sulfur dioxide with oxidized polyolefins, Polym. Degrad. Stab. 15 (1986) 67-79.

[14] V.A. Matyshak, O.V. Krylov, Problems of quantitative spectroscopic measurements in heterogeneous catalysis: molar absorption coefficients of vibrations in adsorbed substances, Kinet. Catal. 43 (2002) 391-407.

[15] T. Iqbal, B.J. Briscoe, P.F. Luckham, Surface plasticization of poly(ether ether ketone), Eur. Polym. J. 47 (2011) 2244-2258.

[16] W.C. Oliver, G.M. Pharr, An improved technique for determining hardness and elastic modulus using load and displacement sensing indentation experiments, J. Mater Res. 7 (1992) 1564-1583.

[17] P. Clément, Détermination des propriétés mécaniques de céramiques poreuses par essais de microindentation instrumentée sphérique (PhD thesis), INSA Lyon, 2013.

[18] J.G. Calvert, J.N. Pitts, Photochemistry, Wiley, New York, 1966.

[19] X. Colin, B. Fayolle, L. Audouin, J. Verdu, About a quasi-universal character of unstabilised polyethylene thermal oxidation kinetics, Polym. Degrad. Stab. 80 (2003) 67-74.

[20] X. Colin, L. Audouin, J. Verdu, Determination of thermal oxidation rate constants by an inverse method. Application to polyethylene, Polym. Degrad. Stab. 86 (2004) 309-321.

[21] N.V. Zolotova, E.T. Denisov, Mechanism of propagation and degenerate chain branching in the oxidation of polypropylene and polyethylene, J. Polym. Sci. Part A Polym. Chem. 9 (11) (1971) 3311-3320.

[22] N. Khelidj, X. Colin, L. Audouin, J. Verdu, C. Monchy-Leroy, V. Prunier, Oxidation of polyethylene under irradiation at low temperature and low dose rate. Part II- Low temperature thermal oxidation, Polym. Degrad. Stab. 91 (7) (2006) 1598-1605.

[23] A. François-Heude, E. Richaud, A. Guinault, E. Desnoux, X. Colin, Impact of oxygen transport properties on polypropylene thermal oxidation. Part 1: effect of oxygen solubility, J. Appl. Polym. Sci. 132 (5) (2015) 41441.

[24] M. Coquillat, J. Verdu, X. Colin, L. Audouin, R. Nevière, Thermal oxidation of polybutadiene. Part I: effect of temperature, oxygen pressure and sample thickness on the thermal oxidation of hydroxyl-terminated polybutadiene, Polym. Degrad. Stab. 92 (7) (2007) 1326-1333.

[25] A. Viallat, R.P. Bom, J.P. Cohen Addad, S. Perez, Viscosity behaviour of poly(ether imide) in solution: intramolecular interaction and intermolecular association effects, Polymer 20 (33) (1992) 4379-4383.

[26] K.L. Mittal, Polyimides and Other High Temperature Polymers: Synthesis, Characterization and Applications vol. 2, VSP, Utrecht, 2003.

[27] E. Richaud, P. Ferreira, L. Audouin, X. Colin, J. Verdu, C. Monchy-Leroy, Radiochemical ageing of poly(ether ether ketone), Eur. Polym. J. 46 (2010) 731-743.

[28] T.G. Fox, P.J. Flory, Second-order transition temperatures and related properties of polystyrene. I. Influence of molecular weight, J. Appl. Phys. 21 (1950) 581-591.

[29] J. Bicerano, Prediction of Polymer Properties, third ed., Marcel Dekker, New York, 2002.

[30] R. Simha, R.F. Boyer, On a general relation involving the glass temperature and coefficients of expansion of polymers, J. Chem. Phys. 37 (5) (1962) 1003-1007.

[31] D.G. Gilbert, M.F. Ashby, P.W.R. Beaumont, Modulus-maps for amorphous polymers, J. Mater Sci. 21 (9) (1986) 3194-3210. 